\title{
A TECNOLOGIA NO ESPORTE PARALÍMPICO
}

\author{
Vinícius Denardin Cardoso \\ Universidade Estadual de Roraima, Boa Vista, Roraima, Brasil \\ Marcelo de Castro Haiachi \\ Universidade Federal de Sergipe, São Cristóvão, Sergipe, Brasil \\ Alberto Reinaldo Reppold Filho \\ Universidade Federal do Rio Grande do Sul, Porto Alegre, Rio Grande do Sul, Brasil \\ Adroaldo Cezar Gaya \\ Universidade Federal do Rio Grande do Sul, PortoAalegre, Rio Grande do Sul, Brasil
}

\begin{abstract}
Resumo
Atualmente o esporte paralímpico brasileiro cresce aceleradamente em razão de suas recentes e vitoriosas conquistas no cenário internacional. A tecnologia está cada vez mais presente no esporte paralímpico e busca o aprimoramento da performance de atletas de alto rendimento. Neste ensaio, com abordagem qualitativa, procuramos através da análise bibliográfica e reflexão teórica trazer ao leitor um breve conhecimento sobre a tecnologia que vem sendo aplicada no cotidiano de atletas paralímpicos. Consideramos que o conhecimento e o investimento em inovações tecnológicas no esporte paralímpico são fundamentais para um país que busca se manter entre as principais potências paralímpicas mundiais.
\end{abstract}

Palavras-chave: Esporte paralímpico. Atleta paralímpico. Tecnologia.

\section{TECHNOLOGY IN PARALYMPIC SPORT}

\begin{abstract}
Currently the Brazilian Paralympic sport is growing fast due to its recent victories in the international scene. Technology is increasingly present in the Paralympic sport and seeks to improve the performance of high-performance athletes. In this essay, with a qualitative approach, we seek through bibliographical analysis and theoretical reflection to bring to the reader a brief knowledge about the technology being applied in the daily life of Paralympic athletes. We believe that knowledge and investment in technological innovations in Paralympic sport are fundamental to a country that seeks to remain among the main world Paralympic powers.
\end{abstract}

Keywords: Paralympic sport. Paralympic athlete. Technology. 


\section{LA TECNOLOGÍA EN EL DEPORTE PARALÍMPICO}

\section{Resumen}

Actualmente el deporte paralímpico brasileño crece aceleradamente en razón de sus recientes y victoriosas conquistas en el escenario internacional. La tecnologia esta cada vez más presente en el deporte paralímpico y busca el mejoramiento de la performance de atletas de alto rendimento. En este ensayo con enfoque cualitativo, búsqueda de análisis bibliográfico y reflexión teórica, acercar al lector un breve conocimiento sobre la tecnología que se aplica en el cotidiano de atletas paralímpicos. Consideramos que el conocimiento y la inversión en innovaciones tecnológicas en el deporte paralímpico se consideran fundamentales para un país que busca mantenerse entre las principales potencias paralímpicas mundiales.

Palabras clave: Deporte paralímpico. Atleta paralímpico. Tecnología.

\section{Introdução}

O esporte para pessoas com deficiência surgiu como um importante meio na reabilitação física, psicológica e social para pessoas com algum tipo de deficiência. Trata-se de adaptações e modificações em regras, materiais e locais com objetivo de proporcionar a participação desta população em diferentes modalidades esportivas.

A oportunidade da prática esportiva se tornou de grande eficácia para o desenvolvimento de um estilo de vida saudável. É também uma oportunidade de testar as potencialidades dos sujeitos com deficiência, encorajando e possibilitando seu ingresso em práticas esportivas de alto rendimento.

Até algumas décadas atrás, parecia impossível pensar na reabilitação de pessoas com lesões medulares graves, amputações dos membros superiores e inferiores, que levavam na maioria das vezes à invalidez permanente, mas esse panorama mudou completamente após a Segunda Guerra Mundial (1939-1945).

O pós-guerra deixou muitos soldados mutilados, com distúrbios motores, visuais e auditivos. Dessa forma, muitos governos, principalmente da Inglaterra e Estados Unidos (MATTOS, 1994), buscaram ofertar programas de reabilitação a fim de reencaminhá-los para suas atividades rotineiras. Nesse sentido, a prática esportiva foi uma das principais alternativas utilizadas para a reabilitação e uma alternativa que proporcionou resultados positivos para essa finalidade.

Desde então o esporte para pessoas com deficiência ganhou grande destaque no mundo, conquistou muitos adeptos, obteve realizações de diferentes competições, criação de novas modalidades esportivas, adaptação de metodologias e técnicas de treinamento, aprimoramento tecnológico e um grande interesse científico. Tudo isso contribuiu para o crescimento do esporte de alto rendimento para pessoas com deficiência e essa prática esportiva foi denominada Esporte Paralímpico.

O Esporte Paralímpico caracteriza-se pela busca do rendimento máximo, do melhor desempenho em modalidades esportivas praticadas por pessoas em condições de deficiência, reconhecidas pelo International Paralimpyc Commite (IPC) (PARSONS; WINCKLER, 2012).

Especialmente nas duas últimas décadas, o esporte paralímpico tem passado por grandes processos de mudanças com relação ao seu enfoque e à tecnologia empregada. Mais do que terapia, a prática esportiva por atletas com deficiência foca o alto rendimento e esta realidade tem sido alvo de atenção de pesquisadores nas mais diversas áreas: Ciências do Esporte, Ciências Biológicas e Saúde, Ciências Sociais e Aplicadas, Psicologia e Educação (SAMULSKI; NOCE, 2002; RIBEIRO; ARAÚJO, 2004; MARQUES et al., 2012; THOMPSON; VANLANDEWIJCK, 2013; REIS, 2014; CARDOSO, 2016). 
Os estudos no esporte paralímpico buscam contribuir para o aprimoramento das capacidades físicas, cognitivas e motoras de indivíduos com deficiências inseridos em atividades esportivas, contribuindo para a valorização das potencialidades e capacidades. Proporcionamse, assim, melhores alternativas para o aproveitamento e rendimento durante a prática esportiva de atletas com deficiência (MARTIN, 2012; BRODTKORB et al., 2008; GROBLER et al., 2015).

Dessa forma, o objetivo deste estudo é refletir acerca da tecnologia, das inovações tecnológicas no esporte paralímpico e da importância de suas aplicações na prática esportiva de atletas com deficiência.

\section{Procedimentos Metodológicos}

Este ensaio possui abordagem qualitativa e procura estudar a tecnologia, as inovações tecnológicas no esporte paralímpico e a importância de suas aplicações na prática esportiva de atletas com deficiência. Através da análise bibliográfica e reflexão teórica, o estudo busca trazer ao leitor o conhecimento sobre esse processo que se faz presente no cotidiano do alto rendimento de atletas paralímpicos.

Assim, através das articulações com a literatura, trazemos algumas discussões e reflexões pertinentes no âmbito do esporte paralímpico. Nessa perspectiva, acreditamos que as colocações aqui postas podem trazer contribuições para o conhecimento das inovações tecnológicas que permeiam o universo do esporte paralímpico.

\section{A tecnologia no esporte paralímpico e suas inovações}

A tecnologia está cada vez mais presente no esporte paralímpico. Trata-se das inovações tecnológicas usadas para o desenvolvimento e aprimoramento de equipamentos e materiais esportivos necessários para a prática do esporte, seja por parte do atleta ou da modalidade, e constituem avanços essenciais para a performance e para melhoria máxima (aspectos físicos, fisiológicos e psicológicos, dentre outros) de atletas de alto rendimento.

De acordo com Burkett (2010), tecnologia é um componente essencial para o esporte paralímpico. Também Thompson e Vanlandewijck (2013) destacam que a tecnologia é um tópico importante no esporte paralímpico em função do acelerado crescimento de materiais utilizados na prática esportiva.

De Almeida et al. (2014) destacam que: as regras esportivas, o desenvolvimento dos sistemas de classificação funcional específico para cada modalidade, os avanços nos equipamentos - como: cadeira de rodas, próteses e outros materiais utilizados em treinamentos e competições esportivas - são alguns dos exemplos da evolução tecnológica dentro do esporte paralímpico.

E essas evoluções dentro do esporte precisam ir ao encontro das necessidades dos atletas de alto rendimento. Dessa forma, é perceptível o avanço que as inovações tecnológicas proporcionam em equipamentos que são indispensáveis para o esporte, a cadeira de rodas e as próteses, por exemplo.

Os diversos modelos de próteses, cadeiras de rodas e acessórios seguem uma rígida regulamentação, mas as regras esportivas não impedem que sejam realizados investimentos e aprimoramentos a cada nova competição paralímpica. As inovações visam proporcionar conforto e, ainda, aprimorar o desempenho dos atletas a cada disputa por medalhas.

Alguns estudos têm demonstrado a influência das inovações tecnológicas no esporte paralímpico. A cadeira de rodas esportiva é o principal equipamento que recebe as inovações da tecnologia. As cadeiras são usadas principalmente no atletismo e em modalidades coletivas, como: basquete, esgrima, rugby, tênis e tênis de mesa. 
Paciorek e Jones (2001), ao avaliarem atletas do atletismo paralímpico, notaram que em provas em que era utilizada cadeira de rodas, os atletas que usavam equipamentos mais sofisticados obtiveram melhores resultados, demonstrando que o resultado pode ter sido em função do avanço da tecnologia nas cadeiras de rodas.

Van der Woude et al. (2001), ao avaliarem o deslocamento na cadeira de rodas esportiva, concluem em seus estudos que: a velocidade da cadeira de rodas é alterada em decorrência do tamanho do aro da cadeira, reduzindo significativamente o tempo de impulso, proporcionando melhor eficiência na propulsão dos atletas.

Além disso, Vanlandewijck et al. (2001), em estudo sobre a biomecânica da propulsão em cadeira de rodas esportivas, destacam resultados importantes no esporte, desde a prevenção de lesões, até o aprimoramento dos equipamentos para melhores desempenho na prática dos diferentes esportes.

Nesse contexto, Leister Filho (2016) destaca que o crescimento do esporte paralímpico tem levado muitas empresas a contribuir com o desenvolvimento tecnológico. É o caso da Bayerische Motoren Werke, a BMW, uma das maiores montadoras de carros do mundo, que também está a serviço da melhora da performance esportiva.

A montadora alemã renovou o acordo com o Comitê Paralímpico dos Estados Unidos antes dos Jogos Paralímpicos do Rio em 2016, desenhando e fabricando as cadeiras de rodas que foram utilizadas pelos atletas americanos na competição. Tudo isso, utilizando os materiais mais leves possíveis (LEISTER FILHO, 2016).

Já a equipe britânica de atletismo utiliza as cadeiras fabricadas pela empresa BAE Systems. No laboratório, na Inglaterra, as cadeiras são testadas em um túnel de vento que também é usado para testar aviões-caça Typhoon da Força Aérea Real britânica. Os dados coletados estão sendo usados para rever a eficiência aerodinâmica da posição sentada dos atletas, visando determinar a melhor posição nas diferentes situações da corrida (CARDOSO, 2016).

Outra modalidade em que a tecnologia se faz presente na prática é no ciclismo paralímpico. O ciclista britânico Jody Cundy ${ }^{1}$ utilizou nos Jogos Paralímpicos de Londres em 2012 um novo modelo de prótese que dispensa a necessidade de tênis, pois se encaixa perfeitamente ao pedal adaptado. Dessa forma, o atleta fica "anexado" à bicicleta. Com aerodinâmica reforçada, a peça foi feita manualmente visando aos Jogos de 2012 (FERRAZ, 2016).

Também o basquete em cadeira de rodas tem se favorecido com a tecnologia. Os assentos das cadeiras de rodas estão cada vez mais voltados para ampliar o conforto e na tentativa de reduzir o risco de lesões nos atletas.

Na equipe britânica de basquete em cadeira de rodas, os assentos são produzidos pela montadora BMW, com objetivo de reduzir a pressão desigual dentro do banco, proporcionando maior velocidade e agilidade na prática esportiva (WRENN, 2012).

Outro equipamento utilizado por atletas de elite e que tem sido amplamente investigado pela tecnologia esportiva são as próteses de membros inferiores, que são utilizadas para suprir a falta de um membro. Na prática esportiva as próteses são projetadas para armazenar energia, podendo proporcionar maior eficiência na marcha/corrida de um atleta com amputação (BRODTKORB et al., 2008).

É crescente o número de estudiosos que tem dado atenção às próteses esportivas nas modalidades paralímpicas. Com objetivo de proporcionar condições para que atletas tenham conforto e segurança no esporte e, ainda, para que possam alcançar resultados expressivos, as próteses desenvolvidas se tornam cada vez mais sofisticadas para o desempenho esportivo.

Grobler, Ferreira e Terblanche (2015) investigaram a evolução, de 1992 até 2012, do desempenho na corrida de atletas com amputações de membros inferiores. Os resultados indicam que os maiores aumentos de desempenho foram observados em atletas com amputações

\footnotetext{
${ }^{1}$ Atleta britânico do ciclismo paralímpico, classe C4, detentor de 4 medalhas de ouro em jogos paralímpicos. 
de membros inferiores (classes T42 $=26 \%$ e T44 $=14 \%{ }^{2}$ ). Os autores destacam que a evolução da tecnologia das próteses de corrida contribuíram para a melhora do desempenho dos atletas ao longo dos anos.

Em estudo com atletas paralímpicos brasileiros, Cardoso (2016) relata a importância da tecnologia aplicada às próteses de corrida no atletismo paralímpico. É destacado que muitos atletas brasileiros iniciam a prática com a prótese do dia a dia para posteriormente fazer uso de próteses de alta tecnologia, aprimorando assim seu desempenho nas provas de atletismo.

O International Paralympic Commitee (IPC) estabelece que os princípios fundamentais referentes à evolução de equipamentos usados durante as competições paralímpicas devem ser: (1) segurança (isto é, para o usuário, outros competidores, oficiais, espectadores e meio ambiente); (2) equidade (isto é, que o atleta não tenha uma vantagem desleal); (3) universalidade (por exemplo, comercialmente disponível para todos e não apenas para determinados atletas ou países); (4) proeza física (ou seja, o desempenho humano é o esforço crítico, não o impacto da tecnologia e equipamentos) (CPB, 2014).

Em 2008, quando o corredor paralímpico sul-africano Oscar Pistorius fez uma tentativa para participar nos Jogos Olímpicos de Pequim utilizando próteses com tecnologia J-Leg de fibra de carbono em forma de "J", chamada de "Flex-Foot Cheetah"' (Ver Figura 1), a imprensa esportiva e a comunidade científica começaram a debater sobre a utilização deste equipamento. (RUSSOMANNO, 2013).

Figura 1 - Oscar Pistorius competindo com as próteses Flex-Foot Cheetah durante os Jogos Olímpicos de Londres 2012.

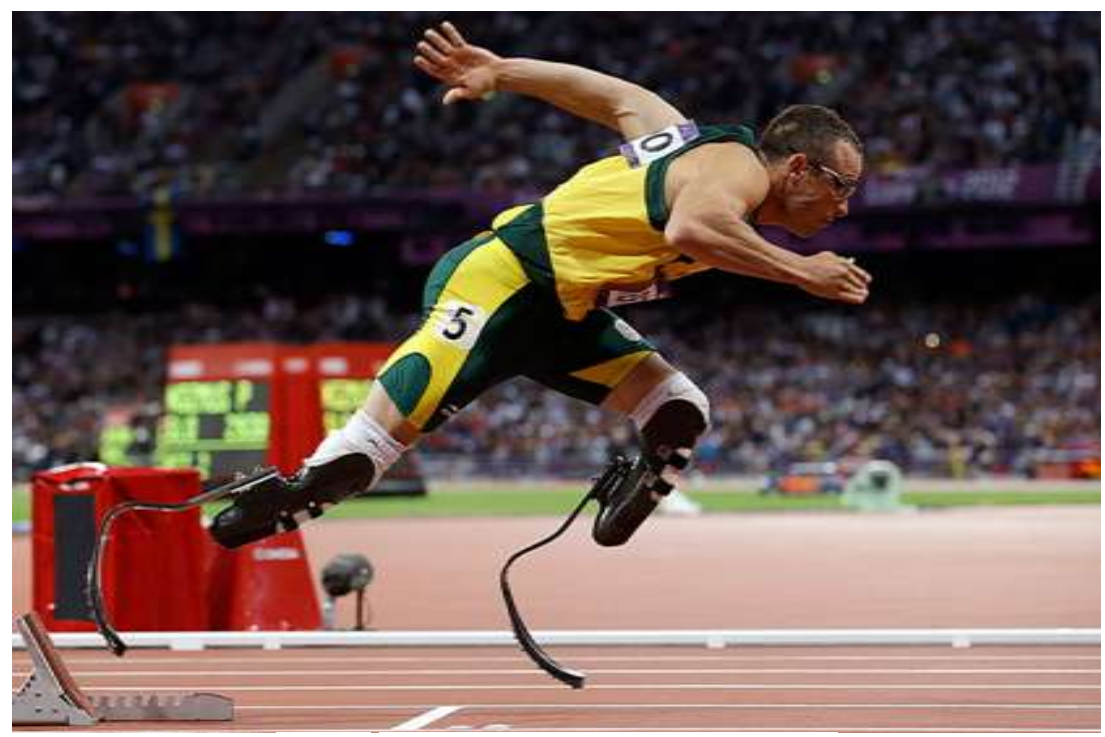

Fonte: AFP Photo/Olivier Morin (2012)

Essa discussão se tornou uma questão importante no campo da biomecânica, biomateriais, ergonomia e fisiologia, e a partir deste momento ampliam-se as discussões sobre as vantagens e desvantagens de se utilizarem as próteses J-leg.

O Comitê Olímpico Internacional (COI) permitiu que Oscar Pistorius pudesse competir no atletismo olímpico com base no estudo publicado no Journal of Applied Physiology por

\footnotetext{
${ }^{2}$ Classe T42/F42: Amputação simples (uma perna) acima do joelho ou algum comprometimento físico similar a tal amputação. Classe T44/F44: Amputação simples (uma perna) abaixo do joelho ou algum comprometimento físico similar a tal amputação. (VERISSIMO; RAVACHE, 2006)

${ }^{3}$ A Flex-Foot Cheetah da empresa Össur é uma prótese projetada com uma tecnologia de carbono exclusiva para armazenar de forma eficiente e liberar a energia produzida pelo usuário durante a corrida, sendo que também absorve níveis elevados de impacto.
} 
Weyland e colaboradores (2009), em que os autores concluíram que a utilização de J-Leg não fornece qualquer vantagem para o atleta.

$\mathrm{O}$ estudo concluiu que as próteses utilizadas pelo atleta Oscar Pistorius fisiologicamente são semelhantes às de um indivíduo com os membros inferiores não amputados (apesar de mecanicamente diferentes). (WEYLAND et al., 2009). Assim, Pistorius se tornou o primeiro atleta bi-amputado a competir em Jogos Olímpicos, ao disputar os 400 metros em Londres 2012.

Essa discussão voltou nos Jogos Paralímpicos de 2012, onde o atleta sul-africano protestou contra o atleta brasileiro Alan Fonteles, nos 200m classe T44. Em Londres, o brasileiro estava usando próteses que o deixaram mais alto, passando de $1,76 \mathrm{~m}$ para $1,81 \mathrm{~m}$, mas o uso dessas próteses foi permitido pelo IPC. O velocista brasileiro conquistou a prova e o ouro paralímpico com um tempo de 21s45, à frente dos 21s52 do sul-africano.

Outro caso semelhante é o do alemão Markus Rehn F44, atleta de salto em distância paralímpico, que atingiu a marca de 8,40m no Campeonato Mundial de Atletismo 2015, em Doha, no Qatar. Marca essa superior à estabelecida pelo medalhista de ouro nos Jogos Olímpicos de Londres 2012, o britânico Greg Rutherford (8,31m).

Em 2016 Rehn participou do Indoor Grand Prix em Glasgow, Escócia, onde foi o vencedor da competição e aguardava posição da International Association of Athletics Federations (IAAF) sobre sua participação nos Jogos Olímpicos do Rio 2016. Rehn tinha encomendado um estudo científico para universidades na Alemanha, Estados Unidos e Japão, na esperança de provar que ele não obtém vantagem sobre os atletas sem deficiência. Em junho de 2016, os resultados indicaram que o atleta tem sua corrida inicial de deslocamento menos eficiente, mas tem um salto mais eficiente que o de outros atletas, levando uma vantagem no movimento final. Dessa forma, o atleta não conseguiu obter autorização para participar dos Jogos Olímpicos do Rio 2016.

Parece que casos como o de Oscar Pistorius e Markus Rehn continuarão a existir no esporte. Cabe aos pesquisadores das ciências do movimento humano e áreas afins aprimorar as regras e as formas de classificação de atletas, para que não haja injustiças na participação destes em Jogos Olímpicos ou em Jogos Paralímpicos.

A tecnologia para atletas paralímpicos não é somente para o cotidiano da pessoa com deficiência, mas também para a possibilidade de atingir a excelência esportiva no esporte de alto rendimento. Próteses, órteses e equipamentos desempenham papel importante na carreira de um atleta; apesar do custo elevado, estes dispositivos podem auxiliar e aprimorar os resultados esportivos.

$\mathrm{O}$ alto custo desses equipamentos pode ser considerado um fator limitante para que alguns países possam investir e proporcionar condições para que seus atletas avancem no esporte paralímpico. Atualmente, próteses de alta performance utilizadas em provas de corrida no atletismo podem custar 150 mil reais (DE ALMEIDA et al., 2014).

Os autores relatam que o Brasil tem ampliado os investimentos em novas tecnologias, com objetivo de reduzir as diferenças que o separam dos grandes campeões paralímpicos (Estados Unidos, Japão, China, Rússia e Grã-Bretanha).

Parcerias entre ciência e tecnologia têm ocorrido em algumas universidades, Comitê Paralímpico Brasileiro (CPB), Instituto Nacional de Tecnologia (INT) e, ainda, na Rede Nacional de Pesquisa e Desenvolvimento em Tecnologia Assistiva, a fim de desenvolver dispositivos para treinamento esportivo de baixo custo para usuários de cadeira de rodas, e, dessa forma, proporcionar a prática esportiva para as modalidades que dependem destes equipamentos. (DE ALMEIDA et al., 2014)

Isso pode favorecer o desenvolvimento tecnológico nas modalidades paraolímpicas no país. Espera-se que os investimentos, em pesquisa ou em produção de materiais esportivos, 
relacionados às constantes inovações tecnológicas sejam cada vez mais comuns à realidade dos atletas paralímpicos brasileiros.

Assim, o principal foco de pesquisadores brasileiros deve ser em como melhorar o desempenho desses atletas em seus treinamentos e competições, do início da sua carreira esportiva até a chegada ao topo. Porém, é necessário estar atento, a fim de que os méritos das conquistas sejam exclusivamente da proeza física dos atletas e não das inovações tecnológicas desenvolvidas pela ciência do esporte.

\section{Considerações finais}

No Brasil o esporte paralímpico vive um momento de grandes resultados esportivos em virtude das suas recentes conquistas: $8^{\circ}$ lugar no quadro geral de medalhas nos Jogos Paralímpicos do Rio de Janeiro 2016, e líder por três edições consecutivas no quadro geral de medalhas nos Jogos Para-Panamericanos (2007, 2011, 2015), principal competição das Américas. Este cenário vitorioso credencia o país como uma potência no movimento paralímpico internacional.

Muitas são as ações governamentais (suporte financeiro, suporte estrutural, suporte tecnológico, entre outros) que vêm sendo realizadas no país com o objetivo de proporcionar o desenvolvimento do esporte paralímpico no Brasil.

Essas ações podem ser consideradas como as razões da grande evolução que o esporte paralímpico alcançou. E com o crescente número de atletas, o surgimento de novas competições e, ainda, novas modalidades esportivas ingressando no calendário paralímpico, é necessário identificar as ações que podem favorecer o aprimoramento do desempenho esportivo dos atletas brasileiros.

Dessa forma, acredita-se que com o apoio de universidades e centros tecnológicos será possível ampliar ainda mais o suporte às inovações tecnológicas para os atletas brasileiros, contribuindo, assim, para a carreira dos atletas paralímpicos e, ainda, para que o país se consolide entre as principais potências mundiais no esporte paralímpico.

\section{Referências}

BRODTKORB, T., M.; HENRIKSSON, K.; JOHANNESEN-MUNK, F.; THIDELL. Costeffectiveness of c-leg compared with non-microprocessor-controlled knees: A modeling approach. Archives of Physical Medicine and Rehabilitation, v. 89, p. 24-30, 2008. Disponível em: <http://www.archives-pmr.org/article/S0003-9993(07)01596-1/fulltext>. Acesso em: 23 maio 2016.

BURKETT, B. Technology in Paralympic sport: performance enhancement or essential for performance? British Journal of Sports Medicine, Londres, v. 44, n. 3, p. 215-220, mar. 2010. Disponível em: <http://bjsm.bmj.com/content/44/3/215>. Acesso em: 02 abr. 2016.

CARDOSO, V. D. O desenvolvimento da carreira esportiva de atletas paraolímpicos brasileiros. 2016. 218 f. Tese (Doutorado em Ciências do Movimento Humano)- Escola de Educação Física, Universidade Federal do Rio Grande do Sul, Porto Alegre, 2016.

Comitê Paralímpico Brasileiro (CPB). Regras e Regulamentos do IPC Athletics 2010-2011, 2014. Disponível em: <http://www.cpb.org.br/wp-content/uploads/2011/12/Regras-oficiaisde-Atletismo-do-IPC-Traduzida.pdf >. Acesso em: 30 dez. 2014. 
DE ALMEIDA, J. J. G.; MIRANDA, T. J.; STORCH, J. A.; HARNISCH, G. A.; BREDARIOL, B. Esporte paralímpico: simbiose entre ciência e tecnologia? ComCiência, Campinas, n. 157 , abr. 2014.20 Disponível em: <http://www.dicyt.com/viewNews.php?newsId=31077>. Acesso em: 20 abr. 2016.

FERRAZ, I. Paratletas apostam na tecnologia para superar seus limites. O Estado de S. Paulo, São Paulo, 28 abr. 2016. Disponível em: <http://esportes.estadao.com.br/noticias/jogosolimpicos,paratletas-apostam-na-tecnologia-para-superar-seus-limites, 10000027569> Acesso em: 30 abr. 2016.

GROBLER, L.; FERREIRA, S.; TERBLANCHE, E. Paralympic sprint performance between 1992 and 2012 International Journal of Sports Physiology and Performance, v. 10, n. 8, p. 1052-1054, nov. 2015. Disponível em: <http://journals.humankinetics.com/doi/abs/10.1123/ijspp.2014-0560>. Acesso em: 24 maio 2016.

LEISTER FILHO, A. BMW fabrica cadeira de rodas de equipe norte-americana competir em Paralimpíadas do Rio. Máquina do Esporte, São Paulo, 9 mar. 2016. Disponível em: $<$ http://maquinadoesporte.uol.com.br/artigo/bmw-fabrica-cadeira-de-rodas-de-equipe-norteamericana-competir-em-paralimpiadas-do-rio_30024.html>. Acesso em: 30 abr. 2016.

MARQUES, R. F. R.; GUTIERREZ, G. L.; DE ALMEIDA, M. A. B. Investigação sobre as configurações sociais do subcampo do esporte paralímpico no Brasil: os processos de classificação de atletas. Revista da Educação Física, Maringá, v. 23, n. 4, p. 515-27, 2012.

MARTIN, J. Mental Preparation for the 2014 Winter Paralympic Games Clinical. Journal of Sport Medicine, Londres, v. 22, n. 1, p. 70-73, jan. 2012. Disponível em: <https://journals.lww.com/cjsportsmed/Fulltext/2012/01000/Mental_Preparation_for_the_201 4_Winter_Paralympic.12.aspx>. Acesso em: 06 abr. 2016.

MATTOS, E. Pessoas portadoras de deficiência física (motora) e as atividades físicas, esportivas, recreativas e de lazer. In: PEDRINELLI, V. J. (Org.). Educação Física e desporto para pessoas portadoras de deficiência. Brasília: MEC-SEDES, SESI, 1994. p. 75-85.

PACIOREK M. J.; JONES J. A. Disability sport and recreation resources. 3. ed. Traverse City: Cooper Publishing Group, 2001. 428p.

PARSONS A.; WINCKLER, C. Esporte e a pessoa com deficiência: contexto histórico. In: MELlO, M. T.; WINCKLER, C (Org.). Esporte Paralímpico. Atheneu: Rio de Janeiro, 2012.

RIBEIRO, S. M; ARAÚJO, P. A formação acadêmica refletindo na expansão do desporto adaptado: uma abordagem brasileira. Revista Brasileira de Ciências do Esporte, v. 25, n. 3, p. 57-70, 2004. 
REIS, R. Políticas públicas para o esporte paralímpico brasileiro. 2014. 114 f. Dissertação (Mestrado em Educação Física)- Setor de Ciências Biológicas, Universidade Federal do Paraná, Curitiba, 2014.

RUSSOMANNO, T. G. Technology as a way to improve performance for the Paralympic athletes. Journal of Ergonomics, v. 3, n. 2, e117, jul. 2013. Disponível em: <https://www.omicsgroup.org/journals/technology-as-a-way-to-improve-performance-for-theparalympic-athletes-2165-7556.1000e117.php?aid=16805>. Acesso em: 28 maio 2016.

SAMULSKI, D.; NOCE, F. Perfil psicológico de atletas paraolímpicos brasileiros. Revista Brasileira de Medicina do Esporte. v. 8, n. 4, p. 157-166, 2002.

THOMPSON, W. R.; VANLANDEWIJCK, Y. C. Science and the Paralympic movement. British Journal of Sports Medicine, v. 47, n. 13, p. 81, 2013. Disponível em: <http://bjsm.bmj.com/content/47/13/811>. Acesso em: 12 nov. 2015.

VAN DER WOUDE, L. H. V.; DALLMEIJER, A. J.; JANSSEN, T. W. J.; VEEGER, D. Alternative modes of manual wheelchair ambulation: An overview. American Journal of Physical Medicine \& Rehabilitation, v. 80, n. 10, p. 765-777, 2001. Disponível em: <https://www.ncbi.nlm.nih.gov/pubmed/11562560>. Acesso em: 30 maio 2016.

VANLANDEWIJCK, Y. C.; THEISEN, D. M.; DALY, D. J. Field test evaluation of aerobic, anaerobic and wheelchair basketball skills performances. International Journal of Sports Medicine, v. 20, p. 548-554, 2001. Disponível em: <https://www.ncbi.nlm.nih.gov/pubmed/10606220>. Acesso em: 30 maio 2016.

VERÍSSIMO, A. W.; RAVACHE, R. Atletismo paraolímpico: manual de orientação para professores de educação física. Brasília: Comitê Paraolímpico Brasileiro, 2006.

WEYAND, P. G.; BUNDLE, M. W.; MCGOWAN, C. P.; GRABOWSKI, A.; BROWN M. B.; KRAM, R.; HERR, H. The fastest runner on artificial legs: different limbs, similar function? Journal of Applied Physiology. v. 107, p. 903-911, 2009. Disponível em: <https://www.ncbi.nlm.nih.gov/pubmed/19541739>. Acesso em: 30 maio 2016.

WRENN, E. From the wheelchair based on an F1 car to the 'Terminator' exo-skeleton suit: How technology is transforming the Paralympics. MailOnline, Londres, 05 set. 2012. Disponível em: <https://www.dailymail.co.uk/sciencetech/article-2198013/Paralympics-2012-Howtechnology-transforming-Games.html>. Acesso em: 30 maio 2016.

Recebido em: 21/06/2017

Revisado em: 02/05/2018

Aprovado em: 04/06/2018

Endereço para correspondência:

vinicardoso@yahoo.com.br

Vinícius Denardin Cardoso

Universidade Estadual de Roraima - UERR

Av. Nazaré Filgueiras, 1812 - Dr. Silvio Botelho, Boa Vista - RR, 69314-550 